Clinical Image

\title{
Diabetic hand: an entity more common than thought
}

Keywords: diabetes, diabetic hand, neuropatia

\section{Introduction}

A 58-year-old female patient, with a history of type 2 diabetes, with a long history of poor medical management. She said she had not noticed any injuries in her hand. She went to medical examination for referring severe edema in the right hand, accompanied by erythema of predominance in the back, pain to the passive mobilization and paresthesias in the fingers. Upon examination, the patient had edema of fingers, pain in the trajectory of the tendinous sheath and pain to the passive extension Figure 1. Patient presented a palmar punctate lesion with a spine injuring the tendinous sheath of the 3rd deep flexor that was not treated on time and was generalized by developing an infectious tenosynovitis of the hand. Diabetic hand is an increasingly common condition in developing countries because a great percentage of its population suffers from this disease, in which there is peripheral neuropathy that generates inadvertent lesions that are usually infected with multiple bacteria.

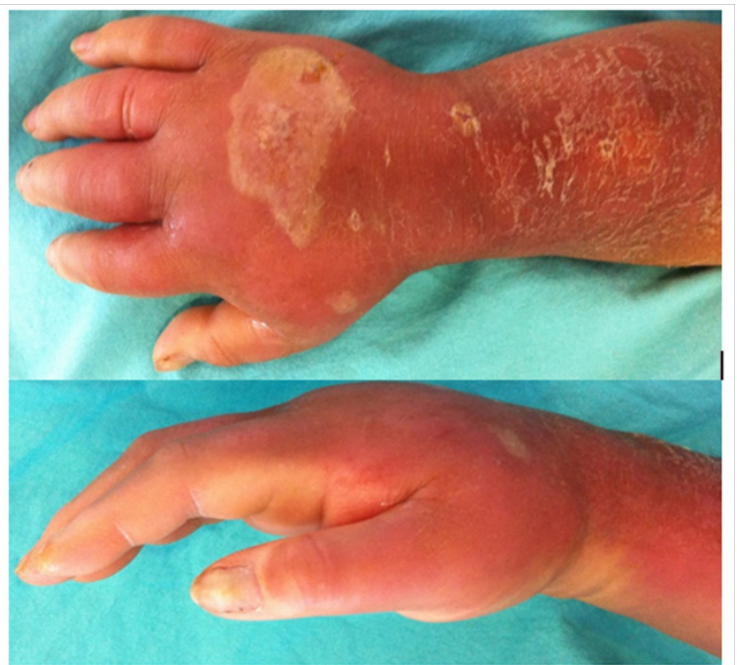

Figure I Diabetic Hand.
Volume 5 Issue 6 - 2018

Julio Palacios Juarez,' Jesus Morales Maza, ${ }^{2}$ Jessica E Figueroa Estrada, ${ }^{3}$ Emmanuel Armando Flores Gonzalez, ${ }^{4}$ Mauricio Zuniga Zamora, ${ }^{5}$ Cristian B Castro Jadan, ${ }^{5}$ Ludivina A Cortes Martinez

'Department of Plastic and Reconstructive Surgery, Hospital Regional de Alta Especialidad de Ixtapaluca, Mexico

2Department of Surgery, Instituto Nacional de Ciencias Medicas y Nutricion Salvador Zubiran, Mexico

${ }^{3}$ American British Cowdray Medical Center, Mexico

${ }^{4}$ Department of Plastic and Reconstructive Surgery, Hospital General de Cuautla, Morelos

${ }^{5}$ Department of Surgery, Hospital Regional de Alta Especialidad de Ixtapaluca, Mexico

${ }^{6}$ Department of Anesthesiology, Hospital Angeles Lomas, Mexico

Correspondence: Julio Palacios Juarez, Department of Plastic and Reconstructive Surgery, Hospital Regional de Alta Especialidad de Ixtapaluca, Mexico,

Email drpayacios.cirplast@icloud.com

Received: October 17, 2017| Published: November 15, 2018

\section{Acknowledgements}

None.

\section{Conflict of interest}

Author declares there is no conflict of interest. 